ISSN: 0975-8232

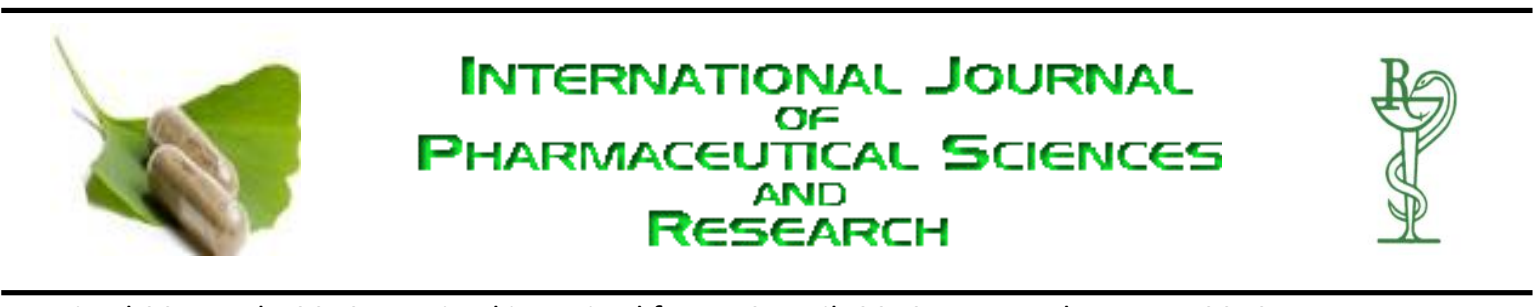

Received 20 March, 2010; received in revised form 10 April, 2010; accepted 15 May, 2010

\title{
DEVELOPMENT AND VALIDATION OF SPECTROFLUORIMETRIC METHOD FOR THE ESTIMATION OF VOGLIBOSE IN BULK AND PHARMACEUTICAL DOSAGE FORM
}

Mallikarjuna Rao N.*, Bagyalakshmi J. and Ravi T. K.

College of Pharmacy, Sri Ramakrishna Institute of Paramedical Science, New Siddapudur, Coimbatore, India

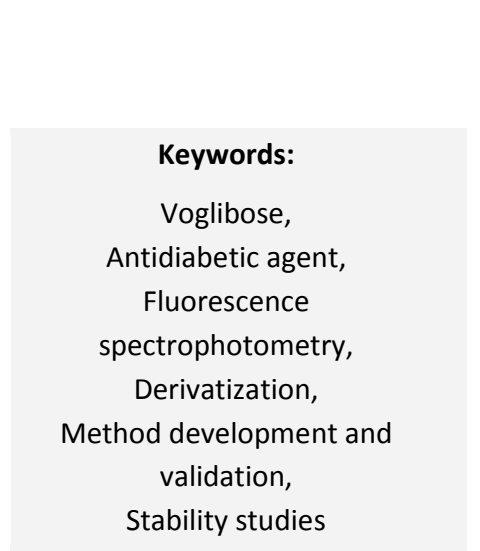

*Correspondence for Author:

MALLIKARJUNA RAO. N

College of Pharmacy, Sri Ramakrishna Institute of Paramedical Science, New Siddapudur, Coimbatore, India

E- mail: mallimpharmmba@gmail.com

\begin{abstract}
A simple, accurate, sensitive, reproducible and cost effective spectrofluorimetric method was developed for the estimation of voglibose in bulk and pharmaceutical formulations. The solvent systems, wavelengths of detection (excitation and emission) were optimized in order to maximize the sensitivity and minimize the cost of analysis for voglibose. Derivatization procedure was employed for analysis. Voglibose showed strong native fluorescence in Methanol having excitation at $282 \mathrm{~nm}$ and emission at 345 $\mathrm{nm}$. Effect of different solvents was thoroughly investigated. All parameters like the effect of different solvents, $\mathrm{pH}$, dilutions, reaction time, temperature and effect of excipients were thoroughly investigated. The linear regression equations obtained by least square regression method for Fluorescence Intensity (FI) and concentration in $\mathrm{ng} / \mathrm{ml}$. The calibration curve was linear in the range from 100 to 350 $\mathrm{ng} / \mathrm{ml}$.The developed method was successfully employed with high degree of precision and accuracy for the estimation of total drug content in commercial tablet formulation of Voglibose (volix).The results of analysis were treated statistically, as per International Conference On Harmonization $(\mathrm{ICH})$ guidelines for validation of analytical procedures, stability studies and by recovery studies. The percentage recovery was found to be in between $98.0 \%$ to $98.5 \%$. The results were found to be in good agreement with the label claims.
\end{abstract}

Available online on www.ijpsr.com 
INTRODUCTION: Voglibose (Fig. 1), 3, 4Dideoxy- 4- [2- hydroxy- 1- (hydroxyl methyl) ethyl]amino- 2- c- (hydroxymethyl)- Depiinositol, has attracted considerable interests due to its wide range of therapeutic and pharmacological properties, including its excellent inhibitory activity against $\alpha$ glucosidase and its action against hyperglycaemia and various disorders caused by hyperglycaemia. Voglibose, a new potent glucosidase inhibitor used for type- 2 diabetes, has shown strong anti-obesity and anti-diabetic activity. As a glucosidase inhibitor, the compound exerts its activity within the gastrointestinal tract of humans. The drug delays glucose absorption and thus, reduces the post-prandial blood glucose peaks ${ }^{1-3}$. Voglibose obtained from organic synthesis processes is similar to structurally related carbohydrates found naturally ${ }^{4,5}$ and has the empirical formula $\mathrm{C}_{10} \mathrm{H}_{21} \mathrm{NO}$.

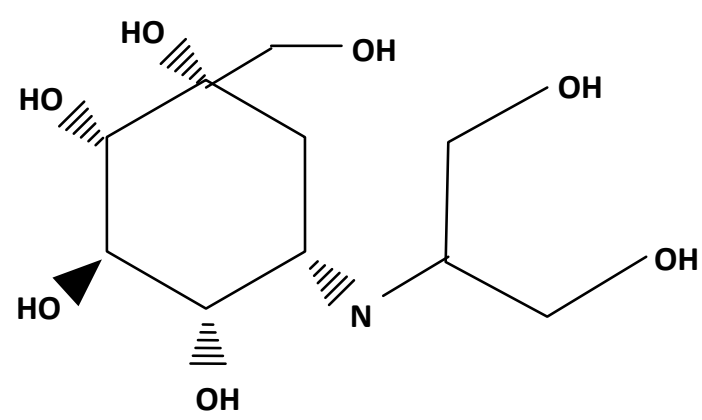

FIG. 1: CHEMICAL STRUCTURE OF VOGLIBOSE

Voglibose was derivatized in order to increase the sensitivity of detection ${ }^{6}$. The derivatization was based on the imination ($\mathrm{C}=\mathrm{N}-)$ of carbonyl group $(-\mathrm{C}=\mathrm{O})$ of voglibose, which was produced by oxidation of the hydroxy methyl group $\left(-\mathrm{CH}_{2}-\mathrm{OH}\right)$ by sodium periodate, with the primary amino group of a fluorophore such as taurine. The main advantage of taurine as a labeling agent is its capability of facilitating highly sensitive fluorescence detection of trace amounts. A survey of literature has not revealed any simple spectrofluorimetric method for estimation of voglibose in pure form and in pharmaceutical dosage form. Fluorescence detection has been preferred due to the interference evident in the chromatograms from UV detection.

The objective of the present study therefore was to develop a simple, sensitive, rapid, precise, accurate, effective and cost effective spectro- fluorimetric analytical methods with better detection/quantification level and devoid of complications and cost of the method were developed for estimation of voglibose in pure form and in their pharmaceutical dosage forms. The developed method was used to estimate the total drug content in commercially available tablets of voglibose (volix). The results of the analysis were validated by statistical methods and as per USP ${ }^{7}, \mathrm{ICH}^{8}$ guidelines. The results of analysis were further validated by recovery studies.

MATERIALS AND METHODS: Pure voglibose was obtained as gift sample from Ranbaxy research laboratories, Gurgaon. All chemicals were of AR grade were procured from SD fine chemicals, Mumbai, India. All fluorescence measurements were done on a scanning spectrofluorimeter (Jasco model FP-777, Tokyo, Japan) with built-in compatible software, link search mode, multiple PMT gain mode automatic wavelength accuracy of $1.5 \mathrm{~nm}$, range $220-750 \mathrm{~nm}$, and $10 \mathrm{~mm}$ quartz cells of $1 \mathrm{~cm}$ path length was used for fluorescence intensity measurement.

Method development: Different solvent systems were used to develop a rugged, 
quick and suitable spectrofluorimetric method for the quantitative determination of voglibose in pure form and in their formulations. The final decision on the suitability of a solvent system for method development of the voglibose was based on cost, sensitivity, solvent noise (fluorescence), quenching effect of the solvent, sample preparation time and steps involved, adaptability of the method for estimation of drugs in their pharmaceutical dosage form and minimization of interference from commonly employed excipients in pharmaceutical formulations.

Selection of Solvent: Methanolic solution of voglibose shown higher fluorescence intensity than other solvents, hence methanol was chosen as the solvent.

Selection of Wavelength: The Relative Fluorescence Intensity (RFI) of voglibose was measured at an excitation wavelength (i.e. activating wavelength, $\lambda_{\text {exc }}$ ) of $282 \mathrm{~nm}$ and an emission wavelength $\left(\lambda_{\mathrm{em}}\right)$ of $345 \mathrm{~nm}$. Fig. $2 \&$ 3 depicts a scan of the excitation fluorescence of the drug obtained of $\lambda_{\text {exc }}$ of $282 \mathrm{~nm}$ and emission fluorescence of $\lambda_{\mathrm{em}}$ of $345 \mathrm{~nm}$. The slit width for excitation and emission was kept as $10 \mathrm{~nm}$. The photomultiplier tube voltage was set at 700 volts.

Calibration Curve: Stock solutions of the drug prepared by dissolving $10 \mathrm{mg}$ of drug in $100 \mathrm{ml}$ of methanol to get a final concentration of $100 \mu \mathrm{g} / \mathrm{ml}$ and derivatized using taurine and sodium periodate. The excitation wavelength and emission wavelength of voglibose in methanol were determined by scanning a suitable dilution of the stock in high pure methanol using the scanning spectrofluorimeter. From the stock solution, various dilutions were made using high pure methanol to obtain dilutions of 50 , $100,200,400,600,800$ and $1000 \mathrm{ng} / \mathrm{ml}$ and the fluorescence intensity was measured for each dilution.

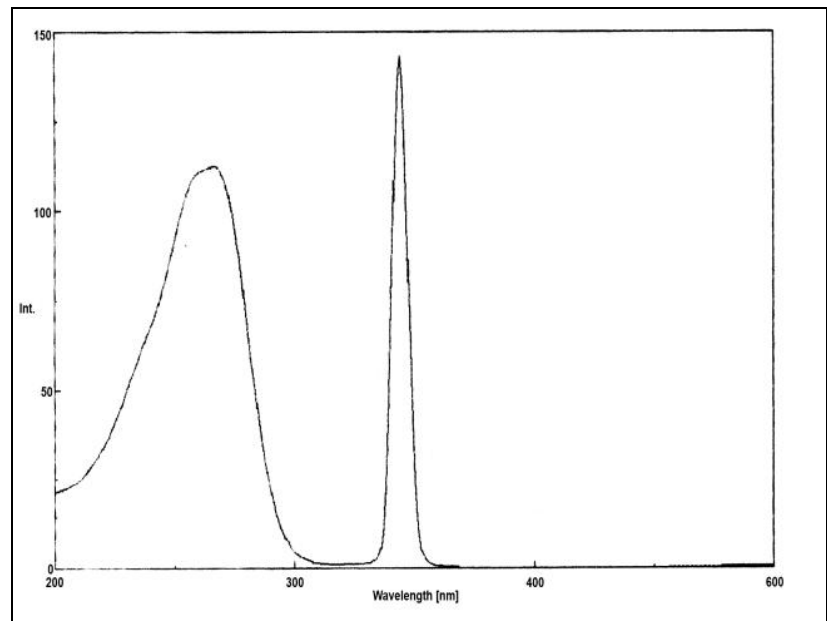

FIG. 2: EXCITATION SPECTRA OF VOGLIBOSE

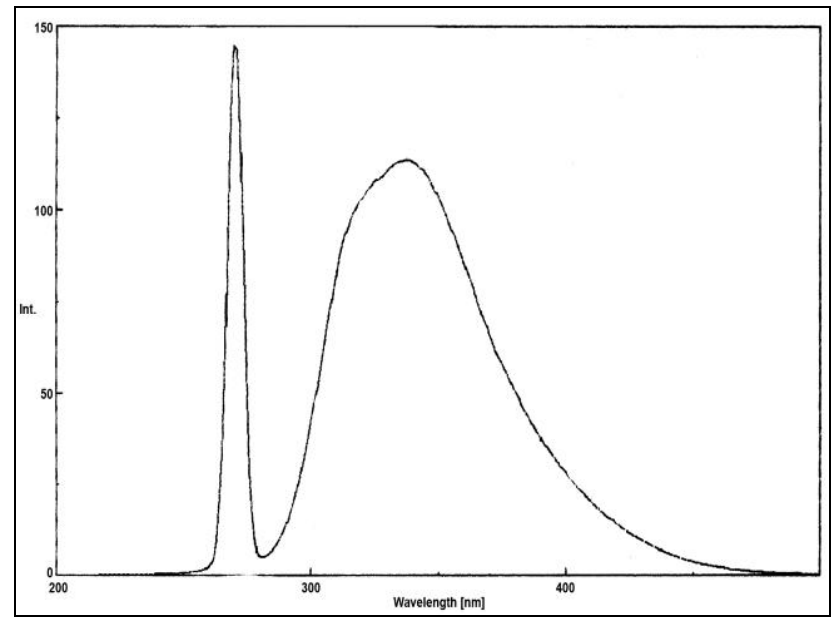

FIG. 3: EMISSION SPECTRA OF VOGLIBOSE

The excitation wavelength and emission wavelength of voglibose in methanol were determined by scanning a suitable dilution of the stock using the scanning spectrofluorimeter. From the stock solution, various dilutions were made using the above solvent system to obtain solutions of 100, 150, 200, 250, 300 and 350 $\mathrm{ng} / \mathrm{ml}$, and fluorescence intensity was 
measured for each dilution. The PMT gain mode was kept at medium for all determinations. The calibration curve values for the voglibose by the proposed method were listed in Table 1.

TABLE 1: FLUORESCENCE INTENSITIES OF VOGLIBOSE

\begin{tabular}{cc}
\hline $\begin{array}{c}\text { CONCENTRATION } \\
(\mathbf{n g} / \mathrm{ml})(\mathbf{X})\end{array}$ & $\begin{array}{c}\text { FLUORESCENCE INTENSITY } \\
(\mathbf{Y})\end{array}$ \\
\hline 100 & 303.24 \\
150 & 427.49 \\
200 & 551.78 \\
250 & 675.01 \\
300 & 799.64 \\
350 & 923.01. \\
\hline
\end{tabular}

Selection of Excitation and Emission Band Width: Fluorescence intensities of $100 \mathrm{ng} / \mathrm{ml}$ solution of Voglibose were recorded with different excitation bandwidth such as 5, 10 and $20 \mathrm{~nm}$. Similarly it is done for fixing emission bandwidth. Both excitation and emission bandwidth were fixed as $10 \mathrm{~nm}$ as the fluorescence intensities and linearity was found to be good. (Table 2)

TABLE 2: FIXING THE BANDWIDTH

\begin{tabular}{ccc}
\hline $\begin{array}{c}\text { MODE OF } \\
\text { MEASUREMENT }\end{array}$ & $\begin{array}{c}\text { BANDWIDTH } \\
\text { (NM) }\end{array}$ & INTENSITY \\
\hline Emission & 5 & 67.14 \\
& $10^{\#}$ & $\mathbf{3 0 3 . 2 8}$ \\
& 20 & 928.38 \\
Excitation & 5 & 76.87 \\
& $10^{\#}$ & $\mathbf{3 5 5 . 3 8}$ \\
& 20 & 964.6 \\
\hline
\end{tabular}

\# selected parameter
RESPONSE TIME: As the excitation and emission bandwidth were fixed as $10 \mathrm{~nm}$ and at different responses the fluorescent intensities were measured. The solution of $100 \mathrm{ng} / \mathrm{ml}$ of Voglibose in methanol was used for the study. Response time of 0.05 was selected. (Table 3)

TABLE 3: FIXING THE RESPONSE

\begin{tabular}{cc}
\hline TIME (SEC) & FLUORESCENCE INTENSITY \\
\hline 0.02 & 334.66 \\
$0.05^{\#}$ & 338.08 \\
0.1 & 336.43 \\
0.25 & 338.66 \\
0.5 & 329.4 \\
1 & 330.6 \\
2 & 330.42 \\
\hline
\end{tabular}

\# selected parameter

SENSITIVITY: As the excitation and emission bandwidth were fixed as $10 \mathrm{~nm}$ and at different responses the fluorescent intensities were measured. The solution of $100 \mathrm{ng} / \mathrm{ml}$ of Voglibose in methanol was used for the study. Sensitivity was fixed as medium hence fluorescence intensities and linearity was satisfactory. (Table 4)

TABLE 4: FIXING THE SENSITIVITY

\begin{tabular}{cc}
\hline SENSITIVITY & INTENSITY \\
\hline Medium $^{\#}$ & 65.24 \\
High & $\mathbf{3 0 4 . 9 2}$ \\
& 952 \\
\hline
\end{tabular}

\# selected parameter 
Method Validation: The developed method was validated as per $\mathrm{ICH}$ guidelines ${ }^{9,} 10$. Following procedures were employed to determine various validation parameters of the developed method.

Linearity ${ }^{11}$ : A stock solution of Voglibose $1000 \mu \mathrm{g} / \mathrm{ml}$ was prepared. For establishing linearity, six separate series of solutions of the drug, 50 to $1000 \mathrm{ng} / \mathrm{ml}$ were prepared from the stock solution; derivatized and analyzed. Linearity of the method was conformed by plotting calibration concentration of the drug (i.e. sensitivity) vs. fluorescence intensity. The linearity in the selected medium (methanol) was found to range in between $100-350 \mathrm{ng} / \mathrm{ml}$. The correlation coefficient $\left(r^{2}\right)$ was found to be 0.999. The graphical representation of linearity is depicted in figure 4.

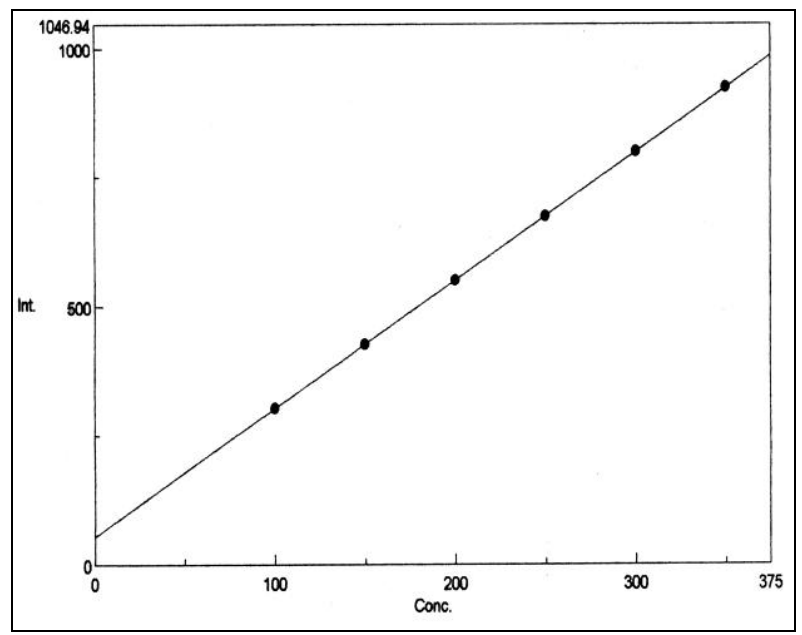

FIGURE 4: CALIBRATION GRAPH OF VOGLIBOSE

Accuracy (Recovery studies): Recovery studies were done at two different levels; i.e. $50 \%$ and $100 \%$. Recovery studies were performed to keep an additional check on the accuracy of the developed assay methods. Known amount of pure drug was added to pre-analyzed samples of commercial dosage forms. The percent analytical recovery was calculated by comparing concentration obtained from the spiked samples with actual added concentration. The percentage recovery levels lies in between $98.0 \%$ to $98.5 \%$. Recovery results demonstrated that the proposed method was unaffected in the presence of formulation excipients and thus highly accurate. The results of recovery were shown in Table 5.

TABLE 5: RECOVERY STUDIES

\begin{tabular}{ccccc}
\hline \multirow{2}{*}{ DRUG } & \multicolumn{2}{c}{ \%RECOVERY } & \multicolumn{2}{c}{ \%RSD } \\
\cline { 2 - 5 } & $\mathbf{5 0 \%}$ & $\mathbf{1 0 0 \%}$ & $\mathbf{5 0 \%}$ & $\mathbf{1 0 0 \%}$ \\
\hline \multirow{2}{*}{ Voglibose } & 98 & 98.5 & 0.76 & 0.44 \\
\hline
\end{tabular}

Analysis of Commercial Formulation: Twenty five tablets each containing $0.2 \mathrm{mg}$ of Voglibose were weighed, powdered and a quantity equivalent to $5 \mathrm{mg}$ of Voglibose was transferred into a $100 \mathrm{ml}$ volumetric flask, extracted using methanol and made up to the volume with the same. This drug solution was extracted through Whattmann filter paper. Suitable aliquots from the extract were analyzed with the fixed experimental conditions and fluorescence intensities were recorded. The amount of Voglibose present in the sample was found by the method of least squares. The results of analysis of commercial formulation were shown in Table 6.

TABLE 6: ANALYSIS OF FORMULATION

\begin{tabular}{ccccc}
\hline \multirow{2}{*}{ DRUG } & \multicolumn{2}{c}{ AMOUNT (MG/ TABLET) } & $\begin{array}{c}\% \text { LABEL } \\
\text { CLAIM }\end{array}$ & $\begin{array}{c}\text { \%RSD } \\
*\end{array}$ \\
\cline { 2 - 3 } & LABELED & FOUND & & \\
\hline Voglibose & 0.2 & 0.196 & 98.02 & $\begin{array}{c}0.245 \\
8\end{array}$ \\
\hline
\end{tabular}


Precision: Intra-day precision was studied by measuring the fluorescence intensity of the standard drug solutions repeatedly on the same day. Solutions of $100 \mathrm{ng} / \mathrm{ml}$ and 200 $\mathrm{ng} / \mathrm{ml}$ were used for the study. \% RSDs was calculated. Inter-day precision was studied by measuring the fluorescence intensity of the standard drug solutions repeatedly on different days. Solutions of $100 \mathrm{ng} / \mathrm{ml}$ and $200 \mathrm{ng} / \mathrm{ml}$ were used for the study. \% RSDs was calculated. In both inter-day as well as intra-day precision in terms of relative standard deviation (RSD) was determined to be within $1 \%$ limit. The low values of these parameters reflect excellent measurement of accuracy and precision of the proposed method for estimation of Voglibose. (Table 7 \& 8)
TABLE 7: INTRADAY ASSAY

\begin{tabular}{ccc}
\hline CONCENTRATION (ng/ml) & INTENSITY & \%RSD* \\
\hline 100 & 303.24 & \\
& 303.01 & 0.1506 \\
& 302.36 & \\
& 427.49 & \\
200 & 426.56 & 0.1618 \\
& 426.14 & \\
\hline
\end{tabular}

*Mean of six determinations

Stability Studies: The stability of the drug solution was carried out. It was found to be stable at room temperature $11 \mathrm{hrs}$, and at refrigeration $26 \mathrm{hrs}$. (Table 9)

TABLE 8: INTER-DAY ASSAY

\begin{tabular}{|c|c|c|c|c|}
\hline DRUG & CONCENTRATION (ng/ml) & DAYS & INTENSITY & \%RSD* \\
\hline \multirow{16}{*}{ Voglibose } & \multirow{8}{*}{100} & \multirow{4}{*}{$1^{\mathrm{st}}$} & 304.23 & \multirow{4}{*}{0.6844} \\
\hline & & & 302.25 & \\
\hline & & & 301.36 & \\
\hline & & & 299.25 & \\
\hline & & \multirow{4}{*}{$2^{\text {nd }}$} & 280.36 & \multirow{4}{*}{0.4875} \\
\hline & & & 274.36 & \\
\hline & & & 265.36 & \\
\hline & & & 250.36 & \\
\hline & \multirow{8}{*}{200} & \multirow{4}{*}{$1^{\text {st }}$} & 550.64 & \multirow{4}{*}{0.6585} \\
\hline & & & 549.51 & \\
\hline & & & 547.73 & \\
\hline & & & 542.49 & \\
\hline & & \multirow{4}{*}{$2^{\text {nd }}$} & 534.51 & \multirow{4}{*}{0.2332} \\
\hline & & & 534.12 & \\
\hline & & & 532.74 & \\
\hline & & & 531.82 & \\
\hline
\end{tabular}

*Mean of four determinations 
TABLE 9: STABILITY STUDIES

\begin{tabular}{ccccc}
\hline & \multicolumn{4}{c}{ ABSORBANCE OF THE DRUG } \\
\cline { 2 - 5 } CONCENTRATION (NG/ML) & TIME & $\begin{array}{c}\text { AT ROOM } \\
\text { TEMPERATURE }\end{array}$ & TIME (HRS) & REFRIGERATION \\
\hline & 0 & 799.64 & 0 & 799.64 \\
& $30 \mathrm{~min}$ & 791.64 & 5 & 783.64 \\
& $1 \mathrm{hr}$ & 775.65 & 7 & 751.66 \\
& $2 \mathrm{hr}$ & 759.65 & 14 & 719.67 \\
& $5 \mathrm{hr}$ & 735.66 & 16 & 687.69 \\
& $9 \mathrm{hr}$ & 687.69 & 19 & 671.69 \\
& $11 \mathrm{hr}$ & 623.71 & 21 & 663.7 \\
& & & 24 & 647.7 \\
& & & 26 & 639.71 \\
\hline
\end{tabular}

RESULTS AND DISCUSSION: Methanolic solution of Voglibose gave higher fluorescence intensity than in other solvents, hence methanol was chosen as the solvent. The excitation and emission wavelengths were found to be linear between 100 to $350 \mathrm{ng} / \mathrm{ml}$; with $\mathrm{r}^{2}=0.999$. The percentage recovery studies revealed that the recovery levels lie between $98.0 \%$ and $98.5 \%$. The \% RSD for intra- and inter- day variations in the analysis was found to be stable for $11 \mathrm{hrs}$ at room temperature and $26 \mathrm{hrs}$ at refrigeration.

CONCLUSION: The proposed spectrofluorimetric method for estimation of Voglibose was found to be accurate, precise, and easier compared to other reported methods. The proposed method was valid with respect to linearity, sensitivity, accuracy, reproducibility and precision. The developed method was reproducible and stable, which indicated that this method can be useful for routine quality control of Voglibose in bulk and its solid dosage forms. The sample recoveries in all the investigated formulations were in good agreement with their respective label claims, indicating non- interference of excipients during the spectrofluorimetric estimation of drug.

ACKNOWLEDGEMENTS: The authors are thankful to Dr. Mahesh D. Burande, Bilcare Research Academy and Mr. Vinod Arora, Vice President, R\&D, Ranbaxy for providing samples of drug. I would also extend my thanks to Mr. Nagaraj, Medical Representative, Ranbaxy, Coimbatore for supplying the formulation on time.

\section{REFERENCES:}

1. Y. Yamasaki, N. Katakami, R. Hayaishi-Okano, M. Matsuhisa, Y. Kajimoto, K. Kosugi, M. Hori, Diabetes Res. Clin. Pract. 67(2005) 204-210.

2. K. Watanabe, H. Uchino, C. Ohmura, Y. Tanaka, T. Onuma, R. Kawamori, J. Diabetes Complicat, 18 (2004) 183-186.

3. A. Vichayanrat, S.Ploybutr, M. Tunlakit, P. Watanakejorn, Diabetes Res. Clin. Pract. 55 (2002) 99103.

4. H. Zhang, C.R. Sun, O. Ishurd, Y.J. Pan, L.S. Ding, Carbohydr. Res. 339 (2004) 2027-2030.

5. X. Chen, Y. Zheng, Y.Shen, Curr. Med. Chem. 13 (2006) 109-116.

6. Takehiko Kato, Toshio Kinoshita; Bunseki Kagaku, 35, 869-874 (1996).

7. USP 27, NF 22. The United States Pharmacopeia and the National Formulary, Rockville, MD: The United States Pharmacopeial Convention: 20852, 2004. ISSN: 01957996, ISBN: 1-889788-20-0. 
8. The European agency for the evaluation of medical products, ICH Topic Q2B Note for guidance on validation of analytical procedures: Methodology. GPMP/ICH/281/95, 1996.

9. United States Pharmacoepia, United States Pharmacopial Convention, Inc., 24th Edn. Rockvile, USA, 2003, 2149.

10. International Conference on Harmonization (ICH), Harmonized Tripartite Guidelines on 'Validation of
Analytical Procedures: Methodology', Operational from June 1997, Pub. by The European Agency for the Evaluation of Medicinal products, Human Medicines Evaluation Unit.

11. Huber L. Validation of analytical methods in: Validation and qualification in analytical laboratories, $2^{\text {nd }}$ Ed. New York: Informa Healthcare; 2007. P. 125-54. 